\title{
GAMBARAN BUDAYA KESELAMATAN PROFESIONAL PEMBERI ASUHAN DI KAMAR OPERASI
}

\author{
Hamzah*, Susmiati, Emil Huriani \\ Program Studi Magister Keperawatan, Fakultas Keperawatan, Universitas Andalas \\ *jahidin_hamzah@yahoo.com
}

\begin{abstract}
Abstrak
Budaya keselamatan pasien di rumah sakit di Kota Jambi masih belum cukup baik seperti yang dapat dilihat dari jumlah insiden keselamatan pasien yang dilaporkan dari tim KPRS. Penelitian bertujuan untuk melihat gambaran budaya keselamatan profesional pemberi asuhan (PPA) di kamar operasi rumah sakit umumKota Jambi. Desain Penelitian kuantitatif deskriptif. Alat pengumpulan data menggunakan safety attitude questionnaire yang diadaptasi dalam bahasa Indonesia. Analisa data secara univariat dengan jumlah sampel 126 orang yang terdiri dari dokter spesialis, perawat bedah, penata anestesi, dan apoteker. Total skor budaya keselamatan $(71,08)$, skor rata-rata iklim kerja tim $(75,54)$, iklim keselamatan $(74,83)$, kepuasan kerja $(83,81)$, pengakuan stres $(42,50)$, persepsi manajemen $(69,56)$, dan kondisi kerja $(64,28)$. Penelitian ini merekomendasikan perlu mengembangkan kebijakan terhadap upaya evaluasi penerapan budaya keselamatan pasien di rumah sakit, begitu juga evaluasi terhadap semua standar prosedur operasional ditinjau dari pertimbangan budaya keselamatan serta faktor yang mempengaruhinya.
\end{abstract}

Kata kunci: persepsi profesional pemberi asuhan, kamar operasi, budaya keselamatan pasien

\begin{abstract}
Professional safety culture description in operating rooms. The culture of patient safety in hospitals in Jambi City is still not good enough as can be seen from the number of patient safety incidents reported from the KPRS team. The aim of this study was to look at a picture of the culture of professional safety of care givers (PPA) in the operating room of the Jambi City General Hospital. Descriptive quantitative research design. The data collection tool uses a safety attitude questionnaire that was adapted in Indonesian. Univariate data analysis with a sample of 126 people consisting of specialist doctors, surgical nurses, anesthetists, and pharmacists. Total safety culture score (71.08), average score of team work climate (75.54), safety climate (74.83), job satisfaction (83.81), stres recognition (42.50), management perception (69.56), and working conditions (64.28). This study recommends that it is necessary to develop policies for evaluating the application of patient safety culture in hospitals, as well as evaluating all standard operating procedures in terms of safety culture considerations and the factors that influence them.
\end{abstract}

Keywords: professional perceptions of caregiver, operating room, patient safety culture

\section{Pendahuluan}

Budaya keselamatan pasien adalah nilai, keyakinan, perilaku yang dianut individu dalam suatu organisasi mengenai keselamatan yang memprioritaskan dan mendukung peningkatan keselamatan(1). Upaya menciptakan atau membangun budaya keselamatan merupakan langkah pertama dalam mencapai keselamatan pasien, seperti halnya yang tercantum dalam "Tujuh Langkah Menuju Keselamatan Pasien Rumah Sakit" di Indonesia, yaitumembangun budaya keselamatan pasien(2).

$$
\text { Budaya keselamatan pasien }
$$
merupakan hal yang mendasar didalam pelaksanaan keselamatan di suatu rumah sakit. Rumah sakit harus menjamin penerapan keselamatan pasien pada pelayanan kesehatan yang diberikannya kepada pasien(3). Hal tersebut dikarenakan berfokus pada budaya keselamatan akan menghasilkan penerapan keselamatan pasien yang lebih baik dibandingkan hanya berfokus pada program keselamatan pasien saja(4).

Pentingnya mengembangkan
budaya keselamatan pasien juga ditekankan dalam salah satu laporan Institude of Medicine "To Err is Human" yang menyebutkan bahwa pelayanan kesehatan harus mengembangkan budaya 
keselamatan sedemikian sehingga organisasi tersebut berfokus pada peningkatan reliabilitas dan keselamatan pelayanan pasien(5). Hal ini ditekankan lagi oleh Nieva dan Sorra dalam penelitiannya yang menyebutkan bahwa budaya keselamatan yang buruk merupakan faktor risiko penting yang bisa mengancam keselamatan pasien(6).

Budaya keselamatan pasien di kamar operasi dapat dilihat dari sikap dan persepsi Professional Pemberi Asuhan (PPA) di kamar operasi dalam memberikan pelayanan yang aman untuk pasien dan petugas. Untuk menganalisis budaya keselamatan pasien digunakan kuesioner yang diadopsi dari Safety Attitude Questionnaire-Operating Room (SAQOR)(Sexton et al., 2006) yang terdiri dari teamwork climate (iklim kerja tim), safety climate (iklim keselamatan), perception of management (persepsi manajemen), working condition (kondisi kerja), job satisfaction (kepuasan kerja), dan stres recognition (pengakuan stres).

Penelitian terdahulu tentang budaya keselamatan yang dilihat dari sikap dan persepsi Profesional Pemberi Asuhan (PPA)di kamar operasi rata-rata pada tingkat sedang. Penelitian Calvalho (2015) di Istambul Turkey didapat hasil rata-rata skor budaya keselamatan pasiennya 53,5 $\%$. Berbeda dengan penelitian yang dilakukan Cui, at.all (2017) di China didapat hasil lebih rendah dengan skor rata-rata $41,04 \%$ yang masih dibawah rekomendasi Internasional minimal 75 untuk persepsi yang baik dari budaya keselamatan(7).

Pengukuran budaya keselamatan perlu dilakukan oleh semua rumah sakit(8). Dengan survey budaya keselamatan ini hasilnya akan membantu rumah sakit memahami kinerja rumah sakit saat ini, apa yang masih menjadi masalah dan perlu dilakukan perbaikan.Penelitian ini bertujuan untuk mengetahui gambaran budaya keselamatan pasien (teamwork climate, safety climate, management, working condition, job satisfaction, dan stres recognition) oleh professional pemberi asuhan di kamar operasi rumah sakit umum Kota Jambi.

\section{Metode}

Desain Penelitian kuantitatif deskriptif. Alat pengumpulan data dengan menggunakan safety attitude questionnaire (SAQ) yang diadaptasi dalam bahasa Indonesia. Instrumen terdiri dari dua bagian; bagian pertama berisi 41 pertanyaan tentang persepsi budaya keselamatan sesuai domain SAQ, bagian kedua berisi pertanyaan tentang karakteristik responden; jenis kelamin, usia, kategori profesional, dan lama pengalaman profesional.

Sifat psikometrik: Alpha Cronbach adalah 0,958 untuk teamwork climate, 0,958 untuk safety climate, 0,947 untuk job satisfaction, 0,967 untuk stres recognition, 0,971 untuk perception of manajemen, 0,961 untuk working condition, dan 0,958 untuk item tambahan safety behavior. Skala alat ukur yang digunakan adalah skala Likert. Kriteria penilaian untuk pernyataan positif adalah sebagai berikut: sangat setuju (nilai 100), setuju (nilai 75). ragu-ragu (nilai 50), tidak setuju (nilai 25), dan sangat tidak setuju (nilai 0). Kriteria penilaian untuk pertanyaan negatif adalah kebalikan dari pertanyaan positif. Skala hasil ukur menggunakan data rasio yaitu skor/nilai dari jawaban pernyataan responden.

Penelitian ini telah disetujui oleh Komisi Etik Fakultas Kedokteran Universitas Andalas Padang No : 097/KEP/FK/2019. Prinsip etika berdasarkan pedoman etik kesehatan yang dikeluarkan oleh Komisi Nasional Etik Penelitian Kesehatan. Data dikumpulkan dari profesional pemberi asuhan di kamar operasi dari dua rumah sakit umum di Kota Jambi. Pengumpulan data dilakukan selama lima minggu, mulai tanggal 18 Maret 2019 sampai dengan 18 April 2019 dengan jumlah sampel 126 orang yang terdiri dari dokter spesialis, perawat bedah, penata anestesi, dan apoteker. Analisa data 
menggunakan SPSS versi 20.0. Analisis deskriptif SAQ dilakukan dengan menggunakan mean dan standar deviasi (SD).

\section{Hasil}

Jumlah keseluruhan responden dari kedua rumah sakit sebanyak 126 orang dengan tingkat respon 87,5\%. Karakteristik responden lebih dari setenganya laki-laki $(58,7 \%)$ (table 1). Umur responden dominan kategori dewasa, paling banyak antara umur $30-40$ tahun $(38,1 \%)$. Perawat bedah adalah PPA yang mendominasi profesi di kamar operasi rumah sakit (46,8\%), Dokter spesialis (bedah/anestesi) cukup tinggi partisifasinya yaitu sebanyak 31,7\%, paling sedikit Apoteker/Ass Apoteker 7,9\%. Mengenai lama pengalaman profesional hampir separuh responden memilih antara 1-5 Tahun $(38,9 \%)$. Lebih dari setengahnya responden $(55,6 \%)$ jumlah jam kerjanya 40 jam atau lebih dalam seminggu.

Tabel 1.

Karakteristik responden $(n=126)$

\begin{tabular}{|c|c|c|}
\hline Karakteristik & $\mathrm{f}$ & $\%$ \\
\hline \multicolumn{3}{|l|}{ Jenis Kelamin } \\
\hline Laki-Laki & 74 & 58,7 \\
\hline Perempuan & 52 & 41,3 \\
\hline \multicolumn{3}{|l|}{ Usia } \\
\hline$<30$ tahun & 20 & 15,9 \\
\hline 30-40 tahun & 48 & 38,1 \\
\hline 41-50 tahun & 37 & 29,4 \\
\hline 51-60 tahun & 18 & 14,3 \\
\hline$>60$ tahun & 3 & 2,4 \\
\hline \multicolumn{3}{|l|}{ Profesi / Jabatan } \\
\hline Dokter Spesialis & 40 & 31,7 \\
\hline Perawat Bedah & 59 & 46,8 \\
\hline Penata Anestesi & 17 & 13,5 \\
\hline Apoteker / Ass Apoteker & 10 & 7,9 \\
\hline \multicolumn{3}{|l|}{ Lama Bekerja di Kamar Operasi } \\
\hline$<1$ tahun & 7 & 5,6 \\
\hline $1-5$ tahun & 49 & 38,9 \\
\hline 6-10 tahun & 24 & 19,0 \\
\hline 11-15 tahun & 15 & 11,9 \\
\hline 16-20 tahun & 15 & 11,9 \\
\hline 21 tahun atau lebih & 16 & 12,7 \\
\hline
\end{tabular}

Jumlah Jam Kerja / Minggu

\begin{tabular}{lcc}
\hline$<20$ jam & 7 & 5,6 \\
\hline $20-39$ jam & 49 & 38,9 \\
\hline$>40$ jam & 70 & 55,6 \\
\hline
\end{tabular}

Gambaran budaya keselamatan

Profesional Pemberi Asuhan (PPA) di Kamar Operasi Rumah Sakit Umum di
Kota Jambitahun 2019 dapat dilihat pada tabel 2 berikut ini: 
Jurnal Perawat Indonesia, Volume 3 No 2, Hal 139-144, Agustus 2019 Persatuan Perawat Nasional Indonesia Jawa Tengah

Tabel 2

Rata-rata Budaya Keselamatan per Domain Profesional Pemberi Asuhan (PPA) $(n=126)$

\begin{tabular}{lcc}
\hline \multicolumn{1}{c}{ Domain } & Mean & $\mathrm{SD}( \pm)$ \\
\hline Teamwork Climate & 78,54 & 9,24 \\
\hline Safety Climate & 74,83 & 8,53 \\
\hline Job Satisfaction & 83,61 & 12,63 \\
\hline Stres Recognition & 42,51 & 21,33 \\
\hline Perception of Management & 69,56 & 11,72 \\
\hline Working conditions & 64,28 & 15,45 \\
\hline Safety Behaviors & 75,94 & 11,29 \\
\hline \multicolumn{1}{c}{ Total } & 71,08 & 6,97 \\
\hline
\end{tabular}

Total skor budaya keselamatan berdasarkan domain safety attitude questionnaire (SAQ) adalah 71,08 $(\mathrm{SD} \pm 6,97)$ (table 2). Rata-rata per domain: teamwork climate $(78,54)$, safety climate $(74,83)$, job satisfaction $(83,61)$, stres recognition (42,51), perception of management $(69,56)$, working condition $(64,28)$, dan item tambahan SAQ safety behaviors $(75,94)$.

\section{Pembahasan}

Berdasarkan hasil penelitian yang telah dilakukan didapatkan hasil bahwa Total skor budaya keselamatan berdasarkan keseluruhan domain safety attitude questionnaire (SAQ) adalah 71,08 $(\mathrm{SD} \pm 6,97)$ masih dibawah rekomendasi internasional yaitu 75 persepsi PPA tentang budaya keselamatan di kamar operasi rumah sakit umum di Kota Jambi bervariasi dalam kaitannya dengan domain yang dinilai. Rata-rata 78,54 (SD $\pm 9,24)$ PPA di kamar operasi dari 2 rumah sakit memiliki sikap positip terhadap iklim kerja sama tim. Hasil ini agak lebih positip dari penelitian lainnya. Penelitian yang sama di Brazil (9)dan Turkey(10) menunjukkan rata-rata 58,3 dan 59,27. Penelitian lain dengan menggunakan instrument yang sama di Malaysia(11) ditemukan rata-rata skor teamwork climate 67,6. Peran rumah sakit dalam membangun teamwork dan komunikasi yang efektif sangat dibutuhkan untuk mengurangi insiden patient safety.

Hasil penelitian tentang Iklim keselamatan didapat skor rata-rata 74,83 $(\mathrm{SD} \pm 8,53)$ sedikit dibawah yang sarankan, yaitu 75. Hasil ini hampir sebanding dengan penelitian di Brazil dengan skor rata-rata untuk iklim keselamatan 69,4. Penelitian lain dengan menggunakan instrument yang sama di Irlandia(12) dan Amerika serikat mendapatkan hasil yang sama rata-rata berkisar antara 65,9 hingga 79,7. Disini peran rumah sakit sangat dibutuhkan dalam membuat kebijakan turunan dari permenkes RI No.11 tahun 2017 tentang keselamatan pasien, yang dikhususkan tentang pelaporan insiden, seperti membuat peraturan melindungi pelapor dengan tidak mempublikasikan data pelapor, mengembangkan modul pelaporan, dan dapat juga membuat peraturan pemberian reward bagi ruangan yang memberi laporan terbanyak.

Domain kepuasan kerja mendapat skor ra-rata paling tinggi dari domain budaya keselamatan lainnya. Skor rata-rata kepuasan kerja PPA di kamar operasi rumah sakit di Kota Jambi adalah 83,61 ( $\mathrm{SD} \pm 12,63)$. Hampir sama dengan temuan pada penelitian lainnya, di rumah sakit di Brazil dengan skor rata-rata 77,6 $(\mathrm{SD} \pm 27,8)$. Di Taiwan dan Malaysia skor didapat lebih rendah yaitu 42,1 dan 67,3 . Dengan membandingkan dengan penelitian lainnya, di Kota Jambi PPA nya lebih puas dengan pekerjaan mereka. Terkait hal ini sangat perlu mendapatkan peningkatan support manajerial rumah sakit dalam bentuk motivasi, reward yang mendukung semangat kerja perawat dalam peningkatan penerapan patient safety.

Pengakuan stres merupakan domain dengan skor rata-rata paling rendah dibandingkan domain lainnya yaitu sebesar 42,50. Akan tetapi hasil penelitian ini 
hampir sama dengan hasil penelitian lainnya. Penelitian yang sama dilakukan oleh Ongun dan Interpeler (2017) di Turkey menunjukkan skor rata-rata stres recognitions 33,94. Agak berbeda dengan hasil penelitian di Brazil dan Malaysia mendapat skor rata-rata yang lebih tinggi yaitu 74,8 dan 73,0. Stres kerja walaupun banyak PPA yang membantah ada dampak kelelahan pada kinerja di kamar operasi tidak bisa diabaikan begitu saja. Banyak penelitian menyatakan tingkat stres dan beban kerja yang tinggi menyebabkan kurang optimalnya asuhan yang diberikan, meningkatnya angka pelanggaran terkait dengan patient safety dan terjadinya kesalahan yang lebih sering. Dukungan dari manajemen rumah sakit sangat diperlukan mengurangi beban kerja dengan melakukan pengaturan sumber daya manusia yang disesuaikan dengan jumlah maupun kualifikasi PPA yang dibutuhkan

Domain persepsi terhadap manajemen baik manajemen unit maupun manajemen rumah sakit mendapat skor rata-rata 69,56 $(\mathrm{SD} \pm 11,71)$, dibawah yang disarankan yaitu 75. Hasil penelitian ini hampir sama dengan hasil penelitian sejenis di Malaysia dengan menggunakan instrument yang sama didapat skor ratarata persepsi manajement 62,2. Penelitian di Brazil dan Taiwan mendapat skor ratarata lebih rendah untuk perception of manajement yaitu 44,59 dan 45,2. Model manajemen yang berfokus pada keselamatan pasien. Disamping itu budaya belajar dari kesalahan dan tidak melakukan pelabelan/blaming terhadap petugas yang melakukan kesalahan harus ditunjukkan oleh manajemen/pimpinan rumah sakit.

Sehubungan dengan kondisi kerja, hasil penelitian didapat rata-rata skor untuk kondisi kerja PPA di kamar operasi rumah sakit pemerintah dan swasta di Kota Jambi adalah 64,28 (SD $\pm 15,45)$. Di Jordania, domain working condition ini mencapai skor yang lebih tinggi, setelah proses pendidikan, meningkat rata-rata dari 59,1 menjadi 84,5. Di Brazil dan Turkey dan Brazil mendapat rata-rata domain kondisi kerja 41,9 dan 51,57, dibawah skor minimum yang disaran (75). Rumah sakit perlu menyesuaikan antara beban kerja dengan penyediaan sumber daya manusia (melakukan perhitungan metode WISN), memberikan kesempatan atau memfasilitasi PPA dikamar operasi untuk meningkatkan kemampuan baik kognitif maupun psikomotor, meningkatkan kuantitas dan kualitas peralatan diagnostik dan terapeutik yang mendukung pelayanan Dalam hal tindakan ekstra perilaku untuk keselamatan pasien didapat skor rata-rata 75,94 (SD11,29). Dari 126 responden ratarata $(83,73)$ menganggap dapat berkolaborasi yang baik dengan perawat dan dokter $(82,54)$, dan Apoteker mendapat skor rata-rata paling rendah yaitu 80,95. Lebih dari setengah rata-rata responden $(56,55)$ menganggap penundaan layananan karena gangguan komunikasi adalah hal yang biasa terjadi di kamar operasi. Dalam hal ini tim kamar operasi harus konsisten melakukan setiap item yang dilakukan dalam pembedahan mulai dari the briefing phase, the time out phase, the debriefing phase sehingga dapat meminimalkan setiap risiko yang tidak diinginkan.

\section{Simpulan}

Berdasarkan uraian diatas, Total skor budaya keselamatan $(71,08)$, skor rata-rata iklim kerja tim $(75,54)$, iklim keselamatan $(74,83)$, kepuasan kerja $(83,81)$, pengakuan stres $(42,50)$, persepsi manajemen $(69,56)$, dan kondisi kerja $(64,28)$. upaya yang perlu dilakukan pihak manajemen rumah sakit dalam menciptakan budaya keselamatan dapat melakukan kontrol terhadap sikap dan prilaku (baik prilaku top manajer keperawatan, middle manajer keperawatan, supervisor dan perawat pelaksana). Kemudian meningkatkan pengawasan pada lingkungan yaitu finansial, jenis pekerjaan yang dilakukan, desain pekerjaan, kecepatan kerja, pelatihan yang tersedia serta garis komunikasi. Selanjutnya mengatur dan melakukan evaluasi kembali terhadap 
sistem yang diterapkan seperti cara proses pelaporan kejadian atau insiden yang mengancam keamanan pasien, proses audit, proses inventigasi, komunikasi dan umpan balik. Dalam terciptanya budaya keselamatan yang baik diharapkan seluruh lapisan mulai dari komitmen pimpinan rumah sakit sampai karyawan harus dibenahi melalui upaya-upaya yang telah disarankan.

\section{Daftar Pustaka}

The Joint Commission. 11 Tenets of a Safety Culture. Sentin Event Alert. 2017;(57):57.

KKP-RS. Pedoman pelaporan insiden keselamatan pasien (ikp). 2015;

Fleming M, Wentzell N. Patient Safety Culture Improvement Tool: Development and Guidelines for Use. Healthc Q. 2008;11(spesial Issue):1-11.

El-Jardali A all. Predictors and outcomes of patient safety culture in hospitals. 2018 ;

Medicine I of. To Err Is Human: Building a Safer Health System. 2000. 1-34 p.

Nieva VF, Sorra J. Safety culture assessment: a tool for improving patient safety in healthcare organizations. 2013;12:1-18.

Sexton JB, Helmreich RL, Neilands TB, Rowan K, Vella K, Boyden J, et al. The Safety Attitudes Questionnaire: Psychometric properties, benchmarking data, and emerging research. BMC Health Serv Res. 2006;6:1-11.

KARS. Standar akreditasi rumah sakit edisi 1. Standar Akreditasi Rumah Sakit. 2017;1-421.

Carvalho A all. Safety culture in the operating room of a public hospital in the perception of healthcare professionals. Rev Lat Am Enfermagem [Internet]. 2015;23(6):1041-8. Available from: http://www.scielo.br/scielo.php?scrip $\mathrm{t}=$ sci_arttext\&pid=S0104$11692015000601041 \& \operatorname{lng}=$ en\&tlng= en

Ongun P, Intepeler SS. Operating room professionals' attitudes towards patient safety and the influencing factors. Pakistan J Med Sci. 2017;33(5):1210-4.

Samsuri SE, Pei Lin L, Fahrni ML. Safety culture perceptions of pharmacists in Malaysian hospitals and health clinics: a multicentre assessment using the Safety Attitudes Questionnaire. BMJ Open. 2015;5(11):e008889.

Relihan E, Glynn S, Daly D, Silke B, Ryder S. Measuring and benchmarking safety culture: application of the safety attitudes questionnaire to an acute medical admissions unit. Ir J Med Sci. 2009;178(4):433-9.

Sodikin. (2012). Prinsip Perawatan Demam Pada Anak. Yogyakarta: Pustaka Pelajar.

Soni, A. et al. (2017) 'HHS Public Access', 105(9), pp. 1-13. doi: 10.1111/apa.13445.The.

Sherwood, L. (2011). Fisiologi Manusia dari Sel ke Sistem Edisi 2. Jakarta: EGC.

Sodikin. (2012). Prinsip Perawatan Demam Pada Anak. Yogyakarta: Pustaka Pelajar. 